\title{
Validation of the Polish version of the Hospital Anxiety and Depression Scale in three populations of gynecologic patients
}

Rafał Watrowski ${ }^{1}$, Anke Rohde ${ }^{2}$

1Department of Gynecology and Obstetrics, St. Josefskrankenhaus, Freiburg, Germany 2Department of Gynecologic Psychosomatics, Women's University Hospital Bonn, Germany

Submitted: 7 February 2013

Accepted: 19 April 2013

Arch Med Sci 2014; 10, 3: 517-524

DOI: 10.5114 /aoms.2013.36520

Copyright $\odot 2014$ Termedia \& Banach

\begin{abstract}
Introduction: We analyzed the psychometric properties of the Polish version of the Hospital Anxiety and Depression Scale (HADS) in gynecologic patients.

Material and methods: A total of 252 patients, consisting of three subgroups endocrinologic gynecology $(n=67)$, high-risk pregnancy $(n=124)$, and outpatient gynecologic clinic $(n=61)$ - responded to the HADS, the 12-item Well-being Questionnaire (W-BQ12), the Spielberger State-Trait Anxiety Inventory (STAI), the Beck Depression Inventory-II (BDI-II), and the Hamilton Depression Scale (HAMD). Socio-demographic data were obtained by self-report and interviews. Results: The HADS presented good internal consistency with Cronbach's $\alpha$ at 0.84 and 0.78 for depression and anxiety subscales, respectively, and 0.88 for the whole questionnaire. The principal component analysis with Eigenvalues $>1$ revealed a three-factor structure. Factors 1 ("depression"), and 2 ("anxiety"), as well as the separate Factor 3, explained $23.48 \%, 21.42 \%$, and $12.07 \%$ of the variance, respectively. The items with shared loadings were $A 1, A 3$, and $A 6$. The HADS scores correlated strongly with other depression and well-being scales, but not with STAI-X1/X2.

Conclusions: The Polish HADS revealed a three-factor structure, and 3/7 HADS-A items showed ambiguous factor loadings. All other psychometric properties were satisfactory. The HADS seems to be suitable for use in gynecologic patients, preferentially as an indicator for global psychological distress.
\end{abstract}

Key words: anxiety, depression, gynecologic psychosomatics, health-related quality of life, psychometric scales.

\section{Introduction}

Anxiety and depression are very common, with lifetime prevalences of up to $30 \%[1,2]$. Only $40 \%$ of people suffering from depression or anxiety disorder are correctly diagnosed, and only $5 \%$ to $20 \%$ of depressed or anxious patients receive some form of treatment $[3,4]$. The comorbidity between anxiety and depression is high (50-80\%), and anxiety is often antecedent to depression [5, 6]. Undiagnosed depressive disorder can be fatal, because psychiatric comorbidity remains the main risk factor for suicide, regardless of ethnic and cultural background [7]. In women, the risk for depressive or anxiety disorders is up to three-fold higher than in men $[8,9]$. Almost every second gynecologic patients presenting with somat-

\author{
Corresponding author: \\ Rafał Watrowski \\ Department of Gynecology \\ and Obstetrics \\ St. Josefskrankenhaus \\ Sautierstr. 1 \\ D-79104 Freiburg, Germany \\ Phone: +49/761/2711-2603 \\ Fax: +49/761/2711-2602 \\ E-mail: \\ Rafal.Watrowski@gmx.at
}


ic complaints suffers from mood disorders $[9,10]$. The psychiatric comorbidity usually remains overlooked by gynecologists-obstetricians [10, 11]. Gynecologists are more likely to screen for mood disturbances if they have brief, easy-to-use and validated measures [12].

The Hospital Anxiety and Depression Scale (HADS) is a widely used self-report instrument for measuring anxiety and depression in somatically ill patients [13]. It was published in 1983 and addressed to general hospital outpatient patients [14]. The HADS consists of depression (HADS-D) and anxiety (HADS-A) subscales. The HADS-D focuses on anhedonia, and the HADS-A refers primarily to panic and to generalized anxiety. Somatic symptoms, such as dizziness, headaches, insomnia, anergia, and fatigue, as well as severe psychotic symptoms, are excluded [15]. The authors discourage summarizing the HADS-A and HADS-D scores to the total score (HADS-T) [16]. Nevertheless, the summary score has been repeatedly proposed as a measure for overall emotional distress [17] or health-related quality of life (HRQoL) [18-20]. As a measure for negative affect, the HADS has been proposed for assessing the dimension "subjective evaluations and reactions" in Dijker's quality-oflife-model [19]. The HADS has often been applied to different patient collectives beyond internal medicine (e.g. gynecology), without renewed psychometric validation in those collectives. It could lead to misleading results, as each scale in a new translation or in a new field of application should be proven for its psychometric performance [21]. A recent systematic review (up to 2012) showed that only 50 from 199 potentially relevant studies regarding the factor structure of the HADS delivered sufficient data. From those 50 studies, only two studies were conducted in obstetrical collectives, one in women with breast cancer and none in gynecologic patients [17]. There exist two Polish translations of the HADS. In 1996, Karakuła et al. published the Polish adaptation of the HADS as an appendix to a study about anxiety and depression in psychosomatic-medical disorders. No data about the translation process or psychometric properties were presented [22]. This translation has been used in our pilot validation [23] and - without validation - in three studies concerning anxiety and depression in orthopedic patients [24-26]. In 2000, Majkowicz published his own translation of the modified HADS (the original scale was expanded with items concerning aggression) as the "Polish HADS-M". Unfortunately, the author reported only on internal consistency and convergent validity [27]. The first validation data of the modified "Polish HADS-M" were published in 2011, in a study concerning stroke patients [28]. Our Medline, Scopus and manual searches identified 28 studies using one of the Polish HADS adaptations (remarkably, 23 of them applied the HADS-M).

The purpose of our study was a psychometric analysis of the Polish, non-modified version of the HADS in gynecologic patients.

\section{Material and methods}

The study population $(n=252)$ consisted of three collectives of the Medical University of Poznan: 67 consecutive patients of the Division of Gynecological Endocrinology (GE), 124 patients hospitalized because of high-risk pregnancy (HRP) at the Division of Perinatology, and 61 patients of the outpatient clinic (OUT) of the $1^{\text {st }}$ Division of Gynecology, participating in a study about psychosomatics of pelvic examination. Our study project followed principles in the Declaration of Helsinki. The research project was approved and the publication of the data was permitted by the President of the Poznan University of Medical Sciences. All patients gave informed consent to the study, were young $(<40)$, had no severe comorbidities (especially no psychiatric or oncologic disease), no planned surgery, and Polish was their native language. In the GE, all individuals completed the HADS and the W-BQ12; 66/67 and $37 / 37$ patients also answered the BDI and the $H A M D$, respectively. In HRP, all participants answered the HADS, the W-BQ12, and a questionnaire about the pregnancy course and socio-demographic data. In OUT, the psychometric evaluation consisted of the HADS, the STAI-X1 and the STAI-X2.

\section{Psychometric instruments}

\section{Hospital Anxiety and Depression Scale}

The HADS is a 14-item self-report scale measuring the presence of symptoms of both anxiety (seven items) and depression (seven items) during the past week. Each item is scored from 0 to 3 , so the final score for each subscale is between 0 and 21 . The majority of the studies use the cutoffs of $7 / 8$ for possible and 10/11 for probable anxiety or depression [29].

\section{2-Item Well-being Questionnaire}

The $\mathrm{W}-\mathrm{BQ} 12$ is a generic measure of emotional well-being, designed for use in somatic patients [30]. Similar to the HADS, complaints thought to be somatic were ruled out. Each of the three W-BQ12 subscales consists of 4 items (0-3) and is dedicated to positive well-being (PWB), negative well-being (NWB), and energy (ENE). Subscale scores and a general well-being (GWB) score can be calculated by adding and - if appropriate - reversing the item values. The Polish W-BQ12 was validated by Watrowski and Rohde (submitted for publication) and showed satisfactory psychometric properties. 


\section{Beck Depression Inventory}

The BDI is a 21-question self-report inventory, relating to cognitive, affective, and somatic symptoms of depression. Each response is scored from 0 to 3 , indicating the severity of the symptom and at least the severity of depression (range 0 to 63). In the present study, the 1996-revised form (BDI-II) was applied. Because of items addressing somatic symptoms (tiredness or fatigue, sleep loss, appetite loss) the use of BDI has been considered less suitable for screening for mood disorders in pregnant women [31].

\section{Hamilton Depression Scale}

The Hamilton Depression Scale (HAMD) is a 17item, observer-rating measure of depression. Nine of the items are scored from 0 to 4 . The remaining eight items are scored from 0 to 2 . Total scores range from 0 to 54 . For more than 40 years considered as the "gold standard", the HAMD recently became the focus of criticism because of the unstable factor structure and conceptual doubts [32].

\section{State-Trait Anxiety Inventory}

The State-Trait Anxiety Inventory (STAI) consists of two 20-item forms and is intended to measure the state anxiety (STAI X-1), defined as a transitory emotional response to a stressful situation, and the trait anxiety (STAI X-2), understood as an enduring personality characteristic. Strong positive correlations between STAI scores, BDI and other depression scales suggest construct overlapping [33].

\section{Statistical analysis}

We considered all results as significant at $p<0.05$. We tested the differences between scale scorings with the $U$-test, and the correlations with Spearman's rho $(r)$ coefficient. We analyzed correlations of the (sub)scores of the HADS, BDI, STAI, HAMD, and the W-BQ12 for testing discriminant, convergent and concurrent validity. For examination of inner scale consistency, we used Cronbach's $\alpha$ and related coefficients. For studying the factor structure we applied the principal component analysis with Varimax rotation. The substantial threshold of the factor loading in each item was determined as 0.40 or greater. All statistical analyses were performed with the software package Statistica 5.0 PL (StatSoft Inc.).

\section{Results}

The sociodemographic characteristics of the patients are shown in Table I. All women were young (median age of 22, 24 and 27 years in GE, OUT, and $\mathrm{HRP}$, respectively). The only significant age difference was between GE and HRP. In all groups, most women reached at least the secondary level of education and were satisfied with their material status. The majority of patients in HRP were married, whereas most women in GE were single. Depression, anxiety, and total HADS scores were highest in HRP, followed by OUT and GE, but lower than in other clinical populations studied with the same HADS translation (Table II). The HADS-A and HADS-D scores correlated strongly with each other $(r=0.69)$, and with the HADS-T $(r=0.89-0.94)$ (Table III). No or barely significant ( $p=0.04-0.21)$

Table I. Sociodemographic data of study populations

\begin{tabular}{|c|c|c|c|c|c|}
\hline Parameter & & $\begin{array}{c}\text { Gynecologic } \\
\text { endocrinology (GE) }\end{array}$ & $\begin{array}{c}\text { High-risk } \\
\text { pregnancy (HRP) }\end{array}$ & $\begin{array}{l}\text { Outpatient } \\
\text { clinic (OUT) }\end{array}$ & Total \\
\hline No. of patients, $n(\%)$ & & $67(26.6)$ & $124(49.2)$ & $61(24.2)$ & $252(100)$ \\
\hline Age [years] & Mean (SD) & $21.94(4.03)^{a, b}$ & $27.13(5.47)^{a, c}$ & $23.83(4.51)^{b, c}$ & $24.96(5.38)$ \\
\hline \multirow[t]{3}{*}{ Marital status, $n(\%)$} & $\begin{array}{l}\text { Single (without partner, } \\
\text { or partner not living } \\
\text { in the same household) }\end{array}$ & $49(73.13)$ & $16(12.90)$ & $28(45.9)$ & $93(36.9)$ \\
\hline & $\begin{array}{l}\text { Married (or living with } \\
\text { partner) }\end{array}$ & $18(26.87)$ & $108(87.10)$ & $31(50.82)$ & $157(62.30)$ \\
\hline & Missing data & $0(0)$ & $0(0)$ & $2(3.28)$ & $2(0.79)$ \\
\hline \multirow[t]{4}{*}{ Educational level, $n(\%)$} & Elementary & $18(26.87)$ & $34(27.42)$ & $8(13.11)$ & $60(23.81)$ \\
\hline & Secondary & $38(56.72)$ & $56(45.16)$ & $30(49.18)$ & $124(49.21)$ \\
\hline & University & $11(16.42)$ & $30(24.19)$ & $21(34.43)$ & $62(24.60)$ \\
\hline & Missing data & $0(0)$ & $4(3.23)$ & $2(3.28)$ & $6(2.38)$ \\
\hline \multirow{3}{*}{$\begin{array}{l}\text { Self-perceived } \\
\text { material status, } n(\%)\end{array}$} & Good or very good & $53(79.10)$ & $107(86.29)$ & Not available & $160(63.49)$ \\
\hline & Poor or very poor & $14(20.90)$ & $17(13.71)$ & Not available & $31(12.3)$ \\
\hline & Missing data & $0(0)$ & $0(0)$ & $61(100)$ & $61(24.21)$ \\
\hline
\end{tabular}

Numbers in brackets indicate percent within the (sub)group or standard deviation (SD). Differences between means studied with the $t$-test: $a_{p}(G E v s . H R P)=0.007, b_{p}(G E v s$. OUT $)=0.36, c_{p}$ (HRP vs. OUT) $=0.097$. The missing data in OUT are not reported due to a different study protocol 
Table II. Mean scores and subscores for the HADS in the present study and studies using the same Polish HADS translation

\begin{tabular}{|c|c|c|c|c|c|c|c|}
\hline Variable & GE & HRP & OUT & $\begin{array}{c}\text { Total } \\
\text { gynecologic } \\
\text { population of } \\
\text { the present study }\end{array}$ & $\begin{array}{l}\text { Women and } \\
\text { men with } \\
\text { internal } \\
\text { diseases [22] }\end{array}$ & $\begin{array}{c}\text { Patients } \\
\text { after limb } \\
\text { amputation } \\
{[25]}\end{array}$ & $\begin{array}{l}\text { Patients before/ } \\
\text { after total } \\
\text { hip replace- } \\
\text { ment [26] }\end{array}$ \\
\hline $\begin{array}{l}\text { Number } \\
\text { of patients }\end{array}$ & 67 & 124 & 61 & 252 & $\begin{array}{l}31 \text { (women)/ } \\
32 \text { (men) }\end{array}$ & 45 & 48 \\
\hline Mean age & $21.94(4.03)$ & $27.13(5.47)$ & $23.83(4.51)$ & $24.96(5.38)$ & $\begin{array}{l}51.3(10.4) / \\
51.9(8.6)\end{array}$ & 59.2 (NA) & $56.0(\mathrm{NA})$ \\
\hline $\begin{array}{l}\text { HADS } \\
\text { Anxiety }\end{array}$ & $6.31(3.68)^{a, b}$ & $8.67(4.37)^{a, c}$ & $7.64(3.77)^{b, c}$ & $7.73(4.16)$ & $\begin{array}{l}11.1(5.2) / \\
7.9(3.2)\end{array}$ & $10.5(14.4)$ & $\begin{array}{c}13.71(12.34) / \\
6.53(10.52)\end{array}$ \\
\hline $\begin{array}{l}\text { HADS } \\
\text { Depression }\end{array}$ & $2.87(2.32)^{d, e}$ & $5.60(3.61)^{d, f}$ & $3.64(2.70)^{e, f}$ & $4.40(3.32)$ & $\begin{array}{c}8.0(3.7) / \\
6.4(3.1)\end{array}$ & $8.88(14.6)$ & $\begin{array}{c}10.22(8.23) / \\
4.92(4.9)\end{array}$ \\
\hline $\begin{array}{l}\text { HADS } \\
\text { Total }\end{array}$ & $9.18(5.44) \mathrm{g}, \mathrm{h}$ & $14.27(7.44) \mathrm{g}, \mathrm{i}$ & $11.28(5.81)^{h, i}$ & 12.19 (6.91) & $\begin{array}{l}19.1(\mathrm{NA}) / \\
14.3(\mathrm{NA})\end{array}$ & $19.38(N A)$ & $\begin{array}{c}23.93(\mathrm{NA}) / \\
11.45 \text { (NA) }\end{array}$ \\
\hline
\end{tabular}

$S D$ - standard deviation, NA - not available, GE - gynecologic-endocrinologic group, HRP - patients with pregnancy complications, OUT - patients of a university outpatient clinic. SD in brackets. Differences between GE and HRP ( $p$ as $a, d, g), G E$ and OUT ( $p$ as $b, e, h)$, HRP and OUT ( $p$ as $c, f, i)$ studied with the U-test ( $a_{p}<0.001, b_{p}<0.05,{ }_{p}{ }_{p}=0.12$ (NS), $d_{p}<0.00001, e_{p}<0.08$ (NS), $f_{p}<0.001, g_{p}<0.0001, h_{p}<0.05,{ }^{i} p<0.01$ )

Table III. Discriminative, convergent and concurrent validity of the HADS

\begin{tabular}{|c|c|c|c|c|c|c|c|c|c|c|c|}
\hline \multirow[t]{2}{*}{ Variables } & \multicolumn{3}{|c|}{ HADS } & \multicolumn{4}{|c|}{ Psychological Well-being } & \multicolumn{2}{|c|}{ Depression } & \multicolumn{2}{|c|}{ Anxiety } \\
\hline & $\begin{array}{l}\text { HADS-A } \\
(n=252)\end{array}$ & $\begin{array}{l}\text { HADS-D } \\
(n=252)\end{array}$ & $\begin{array}{c}\text { HADS- } \\
\text { Total } \\
(n=252)\end{array}$ & $\begin{array}{c}\text { W-BQ12- } \\
\text { NWB } \\
(n=190)\end{array}$ & $\begin{array}{c}\text { W-BQ12- } \\
\text { ENE } \\
(n=190)\end{array}$ & $\begin{array}{c}\text { W-BQ12- } \\
\text { PWB } \\
(n=190)\end{array}$ & $\begin{array}{c}\text { W-BQ12- } \\
\text { GWB } \\
(n=190)\end{array}$ & $\begin{array}{c}\text { BDI } \\
(n=66)\end{array}$ & $\begin{array}{l}\text { HAMD } \\
(n=37)\end{array}$ & $\begin{array}{l}\text { STAI-X1 } \\
(n=61)\end{array}$ & $\begin{array}{l}\text { STAI-X2 } \\
(n=59)\end{array}$ \\
\hline HADS-A & - & $0.69^{a}$ & $0.94^{a}$ & $0.80^{a}$ & $-0.60^{a}$ & $-0.46^{a}$ & $-0.77^{a}$ & $0.62^{\mathrm{a}}$ & $0.73^{a}$ & $0.24 \mathrm{~g}$ & $0.26^{f}$ \\
\hline HADS-D & $0.69^{a}$ & - & $0.89^{a}$ & $0.61^{a}$ & $-0.69^{a}$ & $-0.47^{a}$ & $-0.74^{a}$ & $0.60^{a}$ & $0.50^{c}$ & $0.16^{i}$ & $0.37^{d}$ \\
\hline $\begin{array}{l}\text { HADS- } \\
\text { Total }\end{array}$ & $0.94^{a}$ & $0.89^{a}$ & - & $0.77^{a}$ & $-0.68^{a}$ & $-0.50^{\mathrm{a}}$ & $0.81^{a}$ & $0.68^{a}$ & $0.70^{b}$ & $0.22^{h}$ & $0.36^{\mathrm{e}}$ \\
\hline
\end{tabular}

Correlation coefficient Spearman-rho, ${ }^{a_{p}}<0.0000001,{ }^{b_{p}}<0.00001,{ }^{c_{p}}<0.01,{ }_{p}<0.01,{ }^{e_{p}}<0.01,{ }_{p}<0.05, g_{p}=0.06$ (NS), ${ }^{h_{p}}=0.08$ (NS), ${ }^{i} p=0.21$ (NS). BDI - Beck Depression Inventory, HAMD - Hamilton Depression Scale, HADS - Hospital Anxiety and Depression Scale, HADS-A - HADS Anxiety Subscale, HADS-D - Depression Subscale, HADS-Total - HADS Total score, STAI-X1 - State Anxiety Inventory, STAI-X2 - Trait Anxiety Inventory, W-BQ12 NWB - Negative Well-being Subscale, W-BQ12 ENE - Energy Subscale, W-BQ12 PWB - Positive Well-being Subscale, W-BQ12 GWB - General Wellbeing (W-BQ12 Total Score)

correlations existed for HADS, STAI X-1, and STAI $\mathrm{X}-2$ scores. The only significant correlation $(r=0.36$, $p=0.006)$ was between the HADS-T and the STAI $X-2$. The HADS-D and the HAMD correlated moderately $(r=0.5)$. HADS-A, HADS-D, and HADS-T correlated strongly with the W-BQ12-NWB, W-BQ12ENE, and W-BQ12-GWB. The W-BQ12-PWB showed moderate inverse correlations $(r=-0.48-0.50)$ with all HADS measures. The internal consistency, measured as Cronbach's $\alpha$, showed optimal results for both subscales (HADS-A: $\alpha 0.84$ with a mean interitem correlation 0.44 , and HADS-D: $\alpha 0.78$ with mean inter-item correlation 0.34) and for the whole questionnaire $(0.88$, mean inter-item correlation 0.36 ) (Table IV). Also, the " $\alpha$ if item deleted" values (0.81-0.83 for HADS-A, 0.74-0.78 for HADS-D) indicated a high stability of each subscale. The principal component analysis indicated a three-factor structure by eigenvalues $>1$. Factors 1 ("depression") and 2 ("anxiety") explained $23.5 \%$ and $21.4 \%$ of the variance, respectively. Items D4, D5 loaded exclusively on Factor 3, Items A1 and A6 shared the loadings between Factors 2 and 3. This additional Fac- tor 3 accounted for $12 \%$ of the variance explanation. Three of seven anxiety items (A1, A3, and A6) shared the loadings with other factors (Table $\mathrm{V}$ ).

\section{Discussion}

The composition of our study collective (gynecologic endocrinology, obstetrics, outpatient clinic) was representative for the area of non-oncologic, conservative gynecology. The HADS allowed clinically comprehensible comparisons between different subgroups of gynecological patients. Furthermore, as shown in Table II, the scale scorings differed from those provided with the same HADS translation in patients with severe orthopedic conditions (patients before hip replacement or after limb amputation), confirming the differentiation potential of the scale $[25,26]$. Stronger correlations of the HADS-scores with W-BQ12 as compared with BDI or HAMD, no correlation with STAI-X1/X-2, the ambiguous assessment of 3 from 7 anxiety items, and a non-bipartite factor structure suggested the better suitability of the HADS as a general distress 
Table IV. Reliability analysis of the HADS in gynecologic patients $(n=252)$

\begin{tabular}{|c|c|c|c|c|c|}
\hline $\begin{array}{l}\text { HADS Subscale/ } \\
\text { HADS item }\end{array}$ & Cronbach's $\alpha$ & $\begin{array}{l}\text { Mean inter-item } \\
\text { correlation }\end{array}$ & $\begin{array}{l}\text { Scale mean if } \\
\text { item deleted }\end{array}$ & $\begin{array}{c}\text { Corrected item } \\
\text { - total correlation }\end{array}$ & $\begin{array}{l}\alpha \text { if item } \\
\text { deleted }\end{array}$ \\
\hline HADS Anxiety & 0.84 & 0.43 & 7.79 (scale mean) & & \\
\hline A 1 & & & 6.49 & 0.56 & 0.82 \\
\hline A 2 & & & 6.55 & 0.52 & 0.83 \\
\hline A 3 & & & 6.40 & 0.72 & 0.80 \\
\hline A 4 & & & 6.78 & 0.56 & 0.82 \\
\hline A 5 & & & 6.83 & 0.55 & 0.83 \\
\hline A 6 & & & 6.65 & 0.62 & 0.81 \\
\hline A 7 & & & 7.06 & 0.64 & 0.81 \\
\hline HADS Depression & 0.78 & 0.34 & 4.40 (scale mean) & & \\
\hline D 1 & & & 3.86 & 0.58 & 0.74 \\
\hline D 2 & & & 3.82 & 0.61 & 0.73 \\
\hline D 3 & & & 3.86 & 0.61 & 0.73 \\
\hline D 4 & & & 3.30 & 0.42 & 0.77 \\
\hline D 5 & & & 3.85 & 0.36 & 0.78 \\
\hline D 6 & & & 3.85 & 0.47 & 0.76 \\
\hline D 7 & & & 3.87 & 0.49 & 0.75 \\
\hline HADS-Total & 0.88 & 0.36 & 12.19 (scale mean) & & \\
\hline A 1 & & & 10.89 & 0.56 & 0.88 \\
\hline D1 & & & 11.65 & 0.55 & 0.88 \\
\hline A 2 & & & 10.95 & 0.49 & 0.88 \\
\hline D 2 & & & 11.61 & 0.59 & 0.88 \\
\hline A 3 & & & 10.81 & 0.73 & 0.87 \\
\hline D 3 & & & 11.65 & 0.65 & 0.87 \\
\hline A 4 & & & 11.18 & 0.64 & 0.87 \\
\hline D 4 & & & 11.10 & 0.48 & 0.88 \\
\hline A 5 & & & 11.23 & 0.51 & 0.88 \\
\hline D 5 & & & 11.64 & 0.35 & 0.89 \\
\hline A 6 & & & 11.05 & 0.66 & 0.87 \\
\hline D 6 & & & 11.64 & 0.53 & 0.88 \\
\hline A 7 & & & 11.46 & 0.61 & 0.87 \\
\hline D 7 & & & 11.67 & 0.49 & 0.88 \\
\hline
\end{tabular}

Interpretation of " $\alpha$ " as internal consistency indicator: $<0.7$ poor, $0.7-0.9$ good, $>0.9$ probably redundant

measure than as a differentiating tool between anxiety and depression. It is in accordance with the understanding of the HADS as a case finding instrument for overall psychological distress $[17,18]$. The importance of HRQoL is increasingly perceived in somatic diseases, including in the field of gynecology [34]. The eligibility of the HADS in this field is controversial, but a recent European study confirmed the suitability of the HADS as a tool for assessing HRQoL [20]. The Polish HADS showed high internal consistency. Cronbach's $\alpha$ values for each subscale (0.78-0.84) and for the whole HADS
(0.88) lay within the optimal range. The principal component analysis indicated a three-factor structure. However, although a three-factor structure was seen in several studies [35, 36], the item assignment in our study showed some peculiarities. Firstly, Factor 1 (depression) comprised five items from the HADS-D, resulting in fact in an abbreviation of the HADS-D with one additional item 7 (A4) from the HADS-A. Item 7 (addressing psychomotor agitation) is probably the most unstable item within HADS [17]. The most ambiguous item 11 (= A6, "I feel restless as I have to be on the move") shared 
Table V. Principal component analysis of the HADS with Varimax rotation (normalized)

\begin{tabular}{|c|c|c|c|}
\hline Variables & $\begin{array}{c}\text { Factor } 1 \\
\text { (Depression) }\end{array}$ & $\begin{array}{l}\text { Factor } 2 \\
\text { (Anxiety) }\end{array}$ & Factor 3 \\
\hline A1 (Item 1) I feel tense or 'wound up' & 0.230 & 0.504 & $\underline{0.410}$ \\
\hline $\begin{array}{l}\text { A2 (Item 3) I get a sort of frightened feeling as if something awful } \\
\text { is about to happen }\end{array}$ & 0.187 & 0.647 & 0.076 \\
\hline A3 (Item 5) Worrying thoughts go through my mind & $\underline{0.477}$ & 0.655 & 0.139 \\
\hline A4 (Item 7) / can sit at ease and feel relaxed & 0.626 & 0.324 & 0.252 \\
\hline A5 (Item 9) I get a sort of frightened feeling like 'butterflies' in the stomach & 0.116 & 0.750 & 0.077 \\
\hline A6 (Item 11) I feel restless as I have to be on the move & 0.347 & 0.541 & $\underline{0.401}$ \\
\hline A7 (Item 13) / get sudden feelings of panic & 0.259 & 0.757 & 0.082 \\
\hline D1 (Item 2) I still enjoy the things I used to enjoy & 0.687 & 0.093 & 0.286 \\
\hline D2 (Item 4) I can laugh and see the funny side of things & 0.793 & 0.131 & 0.128 \\
\hline D3 (Item 6) / feel cheerful & 0.761 & 0.294 & 0.074 \\
\hline D4 (Item 8) I feel as if I am slowed down & 0.146 & 0.311 & 0.685 \\
\hline D5 (Item 10) I have lost interest in my appearance & 0.183 & -0.032 & 0.819 \\
\hline D6 (Item 12) / look forward with enjoyment to things & 0.542 & 0.344 & 0.070 \\
\hline D7 (Item 14) I can enjoy a good book or radio or TV program & 0.592 & 0.194 & 0.110 \\
\hline Explained variance (eigenvalue > 1) & 3.287 & 2.999 & 1.690 \\
\hline Proportion of variance explained by the given principal component & $23.48 \%$ & $21.42 \%$ & $12.07 \%$ \\
\hline
\end{tabular}

The highest value for each item is bold typed. Additional item loadings > 0.4 (suggesting an ambiguous factor assessment) are underlined in italics

its loadings $(0.35-0.54-0.4)$ quite equally with all three factors. Interestingly, the HADS-D had no items with double loadings. Two HADS-D items (D4 and D5) loaded clearly on the separate Factor 3. Impressive appeared Factor 2 (anxiety): Except for item 7, all original HADS-A items, but no HADS-D item, loaded on it. However, A1 and A6 contributed with shared loadings $>0.4$ to Factor 3 . The interpretation of the underlying construct for Factor 3 is problematic. At the first glance, item D4 ("I feel as if I am slowed down") and D5 ("I have lost interest in my appearance") could address two different (psychomotor and anhedonic) aspects of depression. In fact, and especially in Polish, "slowdown" and "disinterest" appear quite close to each other, and can capture the cognitive impairment in anhedonic depression. Cosco et al. analyzed 50 studies from the last 10 years examining the controversial factor structure of the HADS. 25/50 studies revealed a two-factor structure, $17 / 50$ studies a three-factor structure, 2/50 studies a four-factor structure, and $5 / 50$ studies indicated a one-factor structure [17]. Generally, the assignment of individual items to the specified factor structure or concept (e.g., depression and anxiety) is a well-known problem of most scales. Tests considered "gold standards" also suffer from a questionable factor structure [32, 33]. Imperfections in the ability of rating scales to distinguish between anxiety and depression may depend more on concepts and definitions of these states than on the construction of the scales. For the HADS, it has even been supposed that the three-factor structure best fits the tripartite theory of anxiety and depression (negative affectivity, anhedonic depression, and autonomic anxiety) [35]. It has been proposed that if a clinical state is characterized by both depression and anxiety, then depression should "trump" anxiety [36]. It could apply to the Polish HADS, as only items of the anxiety subscale shared their item loadings with other factors. The trouble with its factor structure becomes relative if the HADS is regarded as a case finding instrument for overall mood impairment [13]. In a study using a similar set of tests (HADS, STAI, BDI), a hierarchical regression analysis revealed that only HADS scores significantly predicted the psychiatric morbidity [37]. Martin et al. combined data from studies conducted in the UK, Hong Kong and Germany, and reanalyzed them regarding the factor structure of the HADS. They concluded that the HADS can still serve as a useful screening tool for anxiety and depression by scoring on the two original scales; however - similar to our findings their evaluation pointed clearly to the underlying three-factor structure of the HADS [38].

In conclusion, our study makes a contribution to the evidence about psychometric performance of the HADS in obstetrics and gynecology. The Polish HADS revealed some satisfactory psychometric properties in gynecologic patients. On the other hand, the three-factor structure differed from the original two-factor structure. Despite this, the HADS 
total score could serve as an indicator for global emotional distress. The major limitation of our study is that it addressed only a particular collective of young, non-surgical, non-oncologic gynecologic patients. Because the HADS is a world-wide used instrument, we need firstly normative HADS data for the healthy Polish population, and secondly, we need extensive HADS validation across many clinical populations.

\section{Acknowledgments}

We are grateful to all the patients who participated in these studies. We thank Prof. Leon Drobnik (President of the Medical University of Poznan in the study period) for the approval of the research project and permission to use the data as part of a PhD research project and for further publications. We thank Prof. Alina Warenik-Szymankiewicz, the head of the Division of Gynecological Endocrinology in the study period, Prof. Zbigniew Słomko, the former head of the Division of Perinatology, and Prof. Zbigniew Friebe, the former head of the $1^{\text {st }}$ Division of Gynecology, University of Medical Sciences, Poznan, Poland, for their support in conducting the study. We thank the Katholischer Akademischer Ausländer-Dienst Bonn for supporting the cooperation with the University of Bonn with a travel grant. We thank Prof. Dr. Elżbieta Kaczmarek of the Department of Bioinformatics and Computational Biology, Medical University of Poznan, and Prof. Dr. Bronisław Ceranka of the Department of Mathematical and Statistical Methods, Poznan University of Life Sciences, for statistical advice.

\section{References}

1. Kessler RC, Berglund P, Demler O, Jin R, Merikangas KR, Walters EE. Lifetime prevalence and age-of-onset distributions of DSM-IV disorders in the National Comorbidity Survey Replication. Arch Gen Psychiatry 2005; 62: 593-602.

2. Kessler RC, Petukhova M, Sampson NA, Zaslavsky AM, Wittchen HU. Twelve-month and lifetime prevalence and lifetime morbid risk of anxiety and mood disorders in the United States. Int J Methods Psychiatr Res 2012; 21: 169-84.

3. Puzyński S. Depressive disorders in general medical practice, particularly in basic health care [Polish]. Psychiatr Pol 2000; 34: 47-58.

4. Balestrieri M, Bisoffi G, Tansella M, Martucci M, Goldberg DP. Identification of depression by medical and surgical general hospital physicians. Gen Hosp Psychiatry 2002; 24: 4-11

5. Wittchen HU, Beesdo K, Bittner A, Goodwin RD. Depressive episodes - evidence for a causal role of primary anxiety disorders? Eur Psychiatry 2003; 18: 384-93.

6. Lamers F, van Oppen P, Comijs HC, et al. Comorbidity patterns of anxiety and depressive disorders in a large cohort study: the Netherlands Study of Depression and Anxiety (NESDA). J Clin Psychiatry 2011; 72: 341-8.

7. Khan TM, Sulaiman SA, Hassali MA. Factors associated with suicidal behaviour among depressed patients in Penang, Malaysia. Arch Med Sci 2012; 8: 697-703.
8. Williams JB, Spitzer RL, Linzer M, et al. Gender differences in depression in primary care. Am J Obstet Gynecol 1995; 173: 654-9.

9. Yonkers KA, Chantilis SJ. Recognition of depression in obstetric-gynecology practices. Am J Obstet Gynecol 1995; 173: 632-8.

10. Bixo M, Sundström-Poromaa I, Björn I, Aström M. Patients with psychiatric disorders in gynecologic practice. Am J Obstet Gynecol 2001; 185: 396-402.

11. Buekens P, van Heeringen K, Boutsen M, Smekens P, Mattellaer P. Depressive symptoms are often unrecognized in gynaecological practice. Eur J Obstet Gynecol Reprod Biol 1998; 81: 43-5.

12. LaRocco-Cockburn A, Melville J, Bell M, Katon W. Depression screening attitudes and practices among obstetrician-gynecologists. Obstet Gynecol 2003; 101: 892-8.

13. Brennan C, Worrall-Davies A, McMillan D, Gilbody S, House A. The Hospital Anxiety and Depression Scale: a diagnostic meta-analysis of case-finding ability. J Psychosom Res 2010; 69: 371-8.

14. Zigmond AS, Snaith RP. The Hospital Anxiety and Depression Scale. Acta Psychiatr Scand 1983; 67: 361-70.

15. Bjelland I, Dahl AA, Haug TT, Neckelmann D. The validity of the Hospital Anxiety and Depression Scale. An updated literature review. J Psychosom Res 2002; 52: 69-77.

16. Snaith RP. The hospital anxiety and depression scale. $\mathrm{Br}$ J Gen Pract 1990; 40: 305.

17. Cosco TD, Doyle F, Ward M, McGee H. Latent structure of the Hospital Anxiety And Depression Scale: a 10-year systematic review. J Psychosom Res 2012; 72: 180-4.

18. Hinz A, Brähler E, Schwarz R, Schumacher J, Stirn A. How useful is the calculation of total scores for questionnaires concerning health related quality of life [German]? Psychother Psychosom Med Psychol 2005; 55: 221-8.

19. The Participation and Quality of Life (PAR-QoL) project. Hospital Anxiety and Depression Scale (HADS). http:// www.parqol.com/page.cfm?id=80. Accessed 26.3.2013.

20. De Smedt D, Clays E, Doyle F, et al. Validity and reliability of three commonly used quality of life measures in a large European population of coronary heart disease patients. Int J Cardiol 2013; 167: 2294-9.

21. Grzesiak M, Kiejna A. Diagnostic questionnaires and their use in epidemiological studies in psychiatry [Polish]. Psychiatr Pol 1999; 33: 519-33.

22. Karakuła H, Grzywa A, Spila B, et al. Use of Hospital Anxiety and Depression Scale in psychosomatic disorders [Polish]. Psychiatr Pol 1996; 30: 653-67.

23. Watrowski R, Rohde A. WHO (Bradley) Well-being Index and Hospital Anxiety and Depression Scale (HADS) in gynecologic and obstetric patients. In: Proceedings of the 31st Congress of Gynecologic Psychosomatic, Hanover 2002 [German]. Neises M, et al. (eds.). Giessen, Psychosozial 2003; 566-73.

24. Badura-Brzoza K, Matysiakiewicz J, Piegza M, Rycerski W, Hese RT. Sociodemographic data and their influence on anxiety and depression in patients after spine surgery [Polish]. Przegl Lek 2005; 62: 1380-3.

25. Badura-Brzoza K, Matysiakiewicz J, Piegza M, Rycerski W, Niedziela U, Hese RT. Sociodemographic factors and their influence on anxiety and depression in patients after limb amputation [Polish]. Psychiatr Pol 2006; 40: 335-45.

26. Badura-Brzoza K, Zajac P, Matysiakiewicz J, et al. The association of quality of life with mental status and sociodemographic data in patients after total hip replacement [Polish]. Psychiatr Pol 2008; 42: 261-9.

27. Majkowicz M. Praktyczna ocena efektywności opieki paliatywnej - wybrane techniki badawcze. In: de WaldenGałuszko K, Majkowicz M (eds.). Ocena jakości opieki 
paliatywnej w teorii i praktyce [Polish]. Akademia Medyczna, Gdańsk 2000; 34-6.

28. Wichowicz HM, Wieczorek D. Screening post-stroke depression using the Hospital Anxiety and Depression Scale [Polish]. Psychiatr Pol 2011; 45: 505-14.

29. Herrmann C. International experiences with the Hospital Anxiety and Depression Scale - a review of validation data and clinical results. J Psychosom Res 1997; 42: 17-41.

30. Riazi A, Bradley C, Barendse S, Ishii H. Development of the Well-being questionnaire short-form in Japanese: the W-BQ12. Health Qual Life Outcomes 2006; 4: 40.

31. Curžik D, Begić NJ. The utility of BDI-II in assessment of pre- and postpartum depression symptoms and their relation to labor pain. Psychiatr Danub 2012; 24: 167-74.

32. Bagby RM, Ryder AG, Schuller DR, Marshall MB. The Hamilton Depression Rating Scale: has the gold standard become a lead weight? Am J Psychiatry 2004; 161. 2163-77.

33. Kennedy BL, Schwab JJ, Morris RL, Beldia G. Assessment of state and trait anxiety in subjects with anxiety and depressive disorders. Psychiatr Q 2001; 72: 263-76.

34. Baczzyk G, Opala T, Kleka P. Quality of life in postmenopausal women with reduced bone mineral density: psychometric evaluation of the Polish version of QUALEFFO-41. Arch Med Sci 2011; 7: 476-85.

35. Dunbar M, Ford G, Hunt K, Der G. A confirmatory factor analysis of the Hospital Anxiety and Depression scale: comparing empirically and theoretically derived structures. Br J Clin Psychol 2000; 39: 79-94.

36. Bramley PN, Easton AM, Morley S, Snaith RP. The differentiation of anxiety and depression by rating scales. Acta Psychiatr Scand 1988; 77: 133-8.

37. Arapaslan B, Soykan A, Soykan C, Kumbasar H. Cross sectional assessment of psychiatric disorders in renal transplantation patients in Turkey: a preliminary study. Transplant Proc 2004; 36: 1419-21.

38. Martin CR, Thompson DR, Barth J. Factor structure of the Hospital Anxiety and Depression Scale in coronary heart disease patients in three countries. J Eval Clin Pract 2008; 14: 281-7. 